\title{
La lucha por la autonomía en el siglo XX en Bolívar: la creación del departamento de Córdoba (1948-1952)
}

\author{
The struggle for autonomy in the twentieth century in Bolivar: the \\ creation of the department of Cordoba (1948-1952)
}

Daldo Gabriel Lambis Mercado 1 iD

Universidad de Cartagena-Colombia

\begin{abstract}
RESUMEN
La lucha por la autonomía en la llamada Provincia de Cartagena o el Bolívar Grande, fue un proceso de larga duración. Desde los mismos inicios de la conquista se presentó una lucha informal, efectuada por los indígenas y los negros cimarrones de los palenques en contra de las formas de explotación humana y la apropiación de tierras por parte de los hispanos y, de igual forma en ser insumisos a la capital provincial (Cartagena). En el siglo XVIII, en el marco del reformismo borbónico, se buscó sujetar "a son de campana" lo que se conoció como la población dispersa o arrochelada. Esta misma política de congregación de pueblos, originó la consolidación de nuevas poblaciones que buscaron por medios legales separarse de Cartagena. Por consiguiente, iniciaran de manera asidua su lucha formal por la autonomía, la cual se constituye en la constante desde finales del siglo XVIII. Para el siglo XX, amparados en las reformas constitucionales descentralizantes las elites de Barranquilla, Montería y Sincelejo adquieren mediante una serie de estrategias políticas la categoría territorial de departamento.
\end{abstract}

Palabras clave: Territorio; División territorial; Autonomía.

\begin{abstract}
The fight for autonomy in the so-called Province of Cartagena or the Bolívar Grande, was a long-lasting process. From the very beginning of the conquest, an informal struggle took place, carried out by the indigenous and the black maroons of the Palenques against the forms of human exploitation and the appropriation of land by Hispanics and, in the same way, in being unsubmissive. to the provincial capital (Cartagena). In the 18th century, within the framework of Bourbon reformism, it was sought to hold "to the bell" what was known as the dispersed or kneeling population. This same policy of congregation of peoples, originated the consolidation of new populations that sought by legal means to separate from Cartagena. Consequently, they will assiduously initiate their formal struggle for autonomy, which has been the constant since the end of the 18th century. For the 20th century, protected by decentralizing constitutional reforms, the elites of Barranquilla, Montería and Sincelejo acquired the territorial category of department through a series of political strategies.
\end{abstract}

Key words: Territory; Territorial Division; Autonomy.

\footnotetext{
${ }^{1}$ Historiador Universidad de Cartagena. daldolambis1980@ gmail.com
} 


\section{PRESENTACIÓN}

La organización político administrativa en el Caribe colombiano, hay que analizarla desde la perspectiva de la larga duración. Desde su llegada, en el siglo XVI, los hispanos fijaron una organización espacial que a partir de los centros urbanos rigieran todo el poder político. En el caso de la Provincia de Cartagena, el centro político de mayor importancia era la ciudad de Cartagena. Sin embargo, esta ciudad “(...) crecería encerrada, amurallada, en sí misma, de espalda a su provincia con un dominio más político y simbólico que efectivo sobre su hinterland, con espacios vacíos, las villas sufragáneas y los pueblos de indios"2. En ese sentido nunca tuvo un dominio total del espacio que le fue adjudicado por la organización político espacial de la corona hispana. Para Marta Herrera Ángel, esta configuración espacial del territorio del Caribe colombiano en la colonia se caracteriza por "la subversión del orden colonial"3. Por consiguiente, en el siglo XVIII las reformas borbónicas se encaminan a tomar el control de las poblaciones que estaban por fuera del sistema colonial español. De esta forma, la Provincia de Cartagena fue sometida a una política de poblamiento y reorganización de su espacio, consistente en reunir a la población dispersa, bajo el sistema jerárquico urbanístico y poblacional hispánico (parroquias y viceparroquias). No obstante, el poco dominio de Cartagena sobre su hinterland ${ }^{4}$, influyó en la pugna entre diferentes poblaciones durante el periodo de la independencia, como fue el caso de Mompox y Cartagena.

Desde finales del siglo XVIII, con las políticas de poblamiento efectuadas por las instituciones coloniales, se consolidaron una serie de poblaciones que se instauran como centros económicos y una clase política que luchó por lograr la autonomía política y administrativa. Las nuevas clases políticas en su disputa por la autonomía instigaron desde las altas esferas del Estado a una constante reorganización del espacio de la antigua Provincia de Cartagena en el siglo XIX e igualmente adquirieron nuevas categorías políticas y administrativas, las cuales pasaron a ser villas, cantones, capital provincial o departamental. En el siglo XX, vemos que el caso de Barranquilla: "La condición económica de Barranquilla frente al resto de las ciudades de la Región Caribe colombiana permitió en el pensamiento de su dirigencia política se gestara a la altura de 1905 la convicción sobre la necesidad de emanciparse de la supremacía política de Cartagena"5. Por consiguiente, esta tendencia autonomista la siguieron poblaciones que más adelante se

\footnotetext{
2 Jorge Conde Calderón, Espacios sociedad y conflictos en la Provincia de Cartagena 1740 - 1815, Barranquilla, Universidad del Atlántico, 1999, pp. 15.

${ }^{3}$ Marta Herrera Ángel, Ordenar para controlar: Ordenamiento espacial y control político en la Llanuras del Caribe y en los Andes Centrales neogranadinos, Siglo XVIII, Bogotá, Academia Colombiana de Historia-Instituto Colombiano de Antropología e Historia, 2002, pp. 203 - 248.

${ }^{4}$ Por eso se habla de analizar en la larga duración el problema de la reorganización político administrativa en lo que fue la Provincia de Cartagena o el Bolívar Grande. En donde desde los mismos inicios de la configuración espacial española, encontramos el origen del poco control de la ciudad sobre su hinterland y, que llegado el siglo XX, va tomar otro matiz; pero amparados en las reformas constitucionales descentralizantes de este siglo.

${ }^{5}$ Jaime Álvarez Llanos, El liberalismo en el departamento del Atlántico 1905-1922, Barranquilla, Universidad del Atlántico, 2002, pp. 47.
} 
convirtieron en emporios económicos y políticos, como fue el caso de Montería y Sincelejo en el siglo XX.

Las luchas por las autonomías y por división territorial en Bolívar es un tema poco abordado por los intelectuales de las ciencias sociales y humanas para el siglo XX. Este tema, cuando es abordado por los historiadores, sólo se remite al plano de lo político cómo si esta fuera la única causa que suscitó la división de este gran departamento en el siglo XX. Después de la Guerra de los Mil Días y de la Separación de Panamá, surgió en todo el país una serie de proyectos autonomistas en la administración de Rafael Reyes (1904 1909). En este período existía el miedo de la separación de Panamá y el rumor de un plan separatista de la parte norte de Colombia. Por lo tanto, la formación de nuevos departamentos obedece no solo a estos principios ${ }^{6}$. Sí sólo analizamos la variable política se tiene una visión parcial de la división territorial del gran departamento de Bolívar, y omitiendo otras causas como las socioeconómicas y, en menor grado, culturales.

Son muchos los vacíos en el conocimiento que se tienen de las causas que estimularon la división territorial del gran departamento de Bolívar. Una de las razones fundamentales que encontramos en el proceso segregacionista fue lo económico. Las nuevas clases políticas aducían que Cartagena se encontraba muy lejos. Todas estas zonas por el abandono de la capital se encontraban en un gran atraso y el único motivo para lograr el progreso era la división. Si percibimos todos estos fundamentos para dividir el departamento, observamos que fue un proceso lento. La primera división ocurrió en 1905 con la creación del departamento del Atlántico con la Ley 17 del 11 de abril de 1905 y con la Ley Número $1^{\circ}$ de $1908^{7}$. El departamento queda dividido así: el de Cartagena, el de Sincelejo y el de Mompox. En total, cuatro contado el formado en 1905. Pero la Ley 65 de $1909^{8}$ acaba con los departamentos que fueron instaurados entre 1905 - 1908. No obstante, las aspiraciones autonomistas siguieron a lo largo de la centuria por lo menos hasta la formación del último departamento el de Sucre en 1966. Todos estos proyectos fueron ideados por las clases políticas de estos territorios, en muchas ocasiones por acuerdos mutuos entre los partidos políticos en este caso Liberales y Conservadores.

Los conceptos empleados en el artículo, uno de ellos es la autonomía aquí lo concebimos como una lucha formal por la autonomía, el cual es realizado de una manera racionalizada en las leyes republicanas del siglo XX por las elites que se fueron constituyendo a lo largo del periodo colonial y republicano. División territorial lo entendemos como la ejecución de parte del Gobierno

\footnotetext{
${ }^{6}$ El período de la Administración Reyes, el proyecto de división territorial (1905 y 1908) a nivel del territorio nacional obedece primordialmente a necesidades básicas de la política nacional. La primera está gestionada al debilitamiento de los viejos centros de poderes regionales que rivalizaron con el gobierno central y que, además ocasionaron la mayoría de las guerras civiles en el siglo XIX, estos estuvieron presentes en Bolívar, Antioquia, Cauca y Santander. La otra causa principal estuvo persuadida por los intereses del gobierno en materia económica, administrativa, fiscal y política.

7 "Ley Número $1^{\circ}$ de 1908. Sobre División territorial", en Archivo Histórico de Cartagena (en adelante se citará por las iniciales AHC), Diario Oficial. Bogotá, agosto 5 de 1908.

8 "Ley Número 65 de 1909. Sobre División territorial”, AHC, Diario Oficial. Bogotá, diciembre 14 de 1909.
} 
central en la aplicación de un proyecto de ley que busca crear una nueva entidad administrativa en este caso departamentos o reestructurar el territorio nacional. El concepto de territorio, lo referimos como una noción geográfica con características jurídico y política, que es controlado por cierto tipo de poder (las elites locales oregionales)

\section{1.- Los departamentos}

Las reformas constitucionales y la promulgación de nuevas leyes anteriores a la de 1968, ponían énfasis en lo departamental; impulsándose la descentralización administrativa en referencia a la opción departamental. Veamos algunas legislaciones a principios de la centuria del XX, que hacen referencia a ello. Lo primero es que como ley los instituía y "los departamentos en que se divide la República, se subdividirán, a su vez, para el servicio administrativo en distritos municipales"9. Igualmente, dentro de la organización territorial departamental se presentaba la división por provincias, estas eran regidas por un prefecto provincial de libre nombramiento hecho por el gobernador. Como el propósito primordial de las leyes de división territorial antes de 1968, fue erigir nuevas unidades administrativas (departamentos), estos, a su vez, estaban regidos por un jefe del poder ejecutivo departamental el cual era el gobernador, cuyas atribuciones eran "(...) dirigir la acción administrativa en el departamento, nombrando y separando sus agentes, reformando y revocando los actos de éstos y dictando las providencias necesarias en todas las ramas de la administración"10. Los gobernadores eran instaurados por libre nombramiento dispuesto por el Jefe del Ejecutivo de la República.

En la forma institucional de los departamentos, además de los gobernadores y los prefectos provinciales, que por ley eran facultados para el ejercicio del poder ejecutivo ${ }^{11}$ en el régimen departamental, existían otras instituciones como es el caso de las llamadas Asambleas Departamentales, que eran de vital importancia en el desempeño administrativo de los departamentos. Las facultades otorgadas por las legislaciones fueron las siguientes: "las Asambleas Departamentales quedan facultadas para crear o suprimir provincias; teniendo en cuenta el mayor incremento de los intereses locales"12. Esta facultad otorgada por la Asamblea Nacional de Colombia, le permite a las Asambleas Departamentales la opción de la distribución y organización territorial departamental. Siguiendo con este enfoque de la organización del territorio departamental facultado por las Asambleas, es el de impulsar la creación de nuevas poblaciones y "arreglar la división territorial del departamento para los efectos fiscales (...) arreglar todo lo

\footnotetext{
9 “Acto Legislativo número 2 de 1908. Por el cual se constituye el Titulo XVIII de la Constitución Nacional y se derogan los actos legislativos $7^{\circ}$ de 1905 y $2^{\circ}$ de 1907", AHC, Gaceta Departamental, Cartagena, agosto 12 de 1908.

10 "Ley número 88 de 1910. En el desarrollo del Acto Legislativo número 3 de 1910", AHC, Gaceta Departamental, Cartagena, diciembre 1 de 1910.

11 "Ley número 20 de 1908. Que adiciona y reforma la Ley 149 de 1888, sobre el régimen político y municipal.", AHC, Diario Oficial, Bogotá, agosto 24 de 1908.

12 "Ley número 88 de 1910. En el desarrollo del acto legislativo número 3 de 1910", AHC, Gaceta Departamental, Cartagena, diciembre 1 de1910
} 
relativo a la organización, recaudación, manejo e inversión de las rentas del departamento"13. También presenta otras atribuciones ${ }^{14}$ entre las cuales se encuentran el votar y fiscalizar el presupuesto de las rentas y los gastos anuales de los departamentos y los municipios que los conforman; igualmente organizar los impuestos y las contribuciones de acuerdo con el sistema tributario nacional.

Estas facultades, otorgadas por las leyes descentralizadoras de principios del siglo XX, muestran cómo funcionaba todo el aparato institucional en el régimen departamental. Observemos algunas sentencias hechas por las asambleas departamentales, la bolivarense. Las leyes facultaron a éstas para la división territorial para efectos fiscalizadores y el manejo de las rentas departamentales y "para la administración fiscal divídase el territorio del departamento en dos Visitadurías Generales que se denominaran: Visitaduría Fiscal del Norte y Visitaduría Fiscal del Sur. La primera comprenderá las provincias de Cartagena, Carmen, Mompox y Magangué y la segunda las de Corozal, Sincelejo, Chinú y Sinú" ${ }^{15}$. Igualmente, se le facultó para la división y organización territorial, en lo referente a la creación de nuevas provincias; para ello se realizaba un riguroso estudio. En los estudios por parte de la Asamblea Departamental se tenía en cuenta lo siguiente: en primer lugar, que la extensión de las nuevas provincias no afectó de las que se fraccionaron. En segundo lugar, que cumplan con un mínimo de población exigidas por las leyes territoriales para ser creadas.

Cuando La Asamblea Departamental de Bolívar efectuó la instauración de la Provincia de Montería, a su vez, se instituyó la de Lorica, donde se manifiesta que la antigua provincia del Sinú fue dividida así: la Provincia del Alto Sinú o de Montería y la del Bajo Sinú o de Lorica. La Ordenanza decía lo siguiente en sus artículos del primero al tercero:

\section{Créase una nueva provincia en las regiones que bañan el Alto Sinú, que se denominará Provincia de Montería con capital Montería. La nueva provincia se compondrá de los siguientes municipios con sus respectivas agregaciones: Montería, Ciénaga de Oro, Cereté y San Pelayo. Los límites entre las Provincias de Montería y Lorica serán los que separaran a las jurisdicciones de los municipios limítrofes entre una y otra provincia ${ }^{16}$.}

Las Asambleas fueron facultadas para reorganización del espacio territorial de los departamentos, como se enfatizó anteriormente y, por consiguiente, para el año de 1923 hace uso de sus facultades legales, efectuando una nueva

\footnotetext{
13 “Ley número 88 de 1910. En el desarrollo del acto legislativo número 3 de 1910”, AHC, Gaceta Departamental, Cartagena, diciembre 1 de 1910.

14 "Ley número 88 de 1910. En el desarrollo del acto legislativo número 3 de 1910", AHC, Gaceta Departamental, Cartagena, diciembre 1 de 1910.

15 "Acta de la sesión del día 12 abril de 1911. Divídase el territorio del departamento en dos Visitadurías Generales", AHC, Gaceta Departamental, Cartagena, abril 18 de1911.

16 "Ordenanza 35. Créase una nueva provincia en las regiones que baña el Alto Sinú", AHC, Gaceta Departamental, Cartagena, abril 20 de 1911.
} 
organización política para mejoras de la administración pública departamental con la Ordenanza 42 sobre división territorial, política y administrativa del departamento ${ }^{17}$. En el artículo $1^{\circ}$ de la ordenanza para efectos administrativos dividió el territorio del departamento en 11 provincias, a saber: Cartagena, Carmen, Corozal, Sincelejo, Morrosquillo, (Tolú), Chinú, San Jorge, (San Marcos), Lorica, Montería, Magangué y Mompós. Con esta Ordenanza Montería recibe la categoría de municipio o de Distrito que era la categoría territorial de aquel entonces. El distrito de Montería estaba compuesto de los corregimientos de Garzones, Arenal, Tres Piedras, El Cerrito, Tres Palmas, La Manta, Tierra Alta y Tucurá.

Todas estas leyes y ordenanzas muestran el propósito de la descentralización que se propugnaba a principios del siglo XX. Vemos que el objetivo del gobierno nacional era dar mayor autonomía a las partes que lo conformaban, los cuales son los llamados departamentos. Ahora miremos un proyecto de ley sobre la descentralización, que en su artículo primero dice lo siguiente: "Cédanse las rentas de Licores Nacionales, degüello de ganado mayor, tabaco, registro y anotación y todos aquellos que ante de la expedición de la Ley $1^{\circ}$ de $1908^{\prime \prime 18}$.

De esta manera, hemos descrito como las leyes territoriales del Estado colombiano fomentaron la institucionalización de los departamentos, las mismas leyes territoriales proponían darle mayor autonomía a estas unidades administrativas:

1. El gobierno está autorizado, conforme a los artículos 13, 14, 22, 24 de la Ley $1^{\circ}$ de 1908.

a. Para reglamentar por medio de decretos la Ley sobre división territorial;

b. Para modificar los limites de los departamentos y de los municipios;

c. Para cambiar la capital de los departamentos nuevamente creados;

d. Para dividir solamente en dos los departamentos que hubieran sido divididos en tres o más.

e. Para suspender la división de cualquiera de los actuales departamentos;

f. Para verificar las correcciones parciales necesarias a la mejor composición y administración de las nueva entidades; y

g. Para participar o retardar la ejecución de la misma Ley.

2. Que para facilitar la implantación de la nueva división territorial decretada por la Asamblea Nacional Constituyente y Legislativa se hace necesario poner paulatinamente en práctica la reforma, principiando por aquellos departamentos cuya división se juzga más oportuno $(\ldots)^{19}$

\footnotetext{
17 "Ordenanza número 42. Sobre división territorial, política y administrativa del departamento", AHC, Gaceta Departamental, Cartagena, abril 27 de1923.

18 "Proyecto de Ley. Sobre descentralización administrativa", AHC, Gaceta Departamental, Cartagena, abril 10 de1909.

19 "Decreto número 916 de 1908. El Presidente de la República de Colombia en sus facultades legales y considerando", AHC, Gaceta Departamental, Cartagena, agosto 31 de 1908.
} 


\section{2.- La autonomía territorial: La creación del departamento de Córdoba}

En esta sección, el propósito es mostrar, por un lado, cuáles fueron las incidencias en la lucha por la división territorial en Bolívar y, por otro lado que causó la creación de nuevos departamentos. En la división territorial influyen los intereses políticos, sociales y económicos. En la lucha por la autonomía, se perciben alegatos que van ser promovidos en todos los proyectos divisionistas. El primero, es que para poder salir del aislamiento y poder progresar ${ }^{20}$ es necesario la división territorial del departamento de Bolívar. De igual forma, se estableció que, aunque los proyectos divisionistas, se presentaban al gobierno central para la creación de los nuevos departamentos, la lucha por la autonomía era en contra de Cartagena, convirtiéndose este argumento en una constante de la lucha formal por la autonomía.

Antes de seguir con la génesis y el desarrollo de los proyectos de división territorial en el antiguo departamento de Bolívar en el siglo XX, es necesario analizar: lo que sigue influyendo de manera persistente en la reorganización de la geopolítica del país es la consolidación de nuevos centros urbanos o políticos ${ }^{21}$. Con el desarrollo económico y político de ciertas poblaciones, como Barranquilla en el siglo XIX, Montería y Sincelejo en el siglo XX. Sin embargo, esta autonomía no hay que mirarla como una disputa en términos que podían llegar a enfrentamiento bélicos o generar violencia. Sino desde el discurso $^{22}$ que se impulsaba en ambas partes. Es decir, que el enfrentamiento no era más que un discurso de interés político, que fue suscitado por las elites. Por un lado, en los nuevos centros políticos se incitaba a través del discurso a la fragmentación del departamento de Bolívar. De otro lado, la elite cartagenera le daba a estos proyectos divisionistas la apreciación de iniciar la desintegración del territorio del departamento, calificándolos como una traición hacia Cartagena.

En la creación del departamento de Córdoba ${ }^{23}$ el nombre insignia, fue el departamento del Sinú. Igualmente, algunos sectores políticos prodepartamentalistas pensaron llamarlo el departamento Entreríos o del Sinú. Simplemente, que por estrategias políticas el nombre que prefirieron (aluden que fue idea del político liberal de Sahagún Miguel F. De la Espriella) "como un acto de justicia con uno de los más insignes próceres de nuestra

\footnotetext{
${ }^{20}$ Remberto Burgos Puche, El General Burgos, Cartagena, Instituto Internacional de Estudios del Caribe, 2000 , pp. 129.

${ }^{21}$ Los centros políticos, al que se hace referencia eran básicamente poblaciones que se fueron consolidando como emporios económicos en una primera instancia. Con el mismo desarrollo económico que éstos presentaron, en ellos se consolida una elite política que en sus aspiraciones estaba la emancipación política de la ciudad de Cartagena y esto se lograría con la división territorial del departamento de Bolívar para la formación de nuevos departamentos.

22 Cuando hablamos de discursos hacemos referencias; por un lado, a los matices de interés político que fomentaba la legalidad de la creación del nuevo departamento con una serie de fundamentos, que eran presentados ante el Gobierno Central. De otro lado, existía el antidiscurso, que era el que promovía la ilegalidad de los nuevos departamentos, con fundamentos presentados al Gobierno; igualmente, eran de interés políticos.

${ }^{23}$ La idea de separación administrativa de las regiones del Sinú y del San Jorge por parte de la elite ganadera monteriana viene desde inicios del siglo XX y, también se hizo sentir a finales de la década de 1930, es precisamente allí donde nace el de impulsar un proyecto político en búsqueda de susodicha separación con el patrocinio del llamado comité prodepartamento de Córdoba con sede en Montería. Véase Jaime Exbrayat, Historia de Montería, Montería, Imprenta Departamental, 1971, pp. $27-31$.
} 
independencia creemos que el nuevo Departamento debe denominarse Córdoba. Nada más honroso para esa entidad que nacer bajo los auspicios del héroe de Ayacucho" 24 . Los cambios que se efectuaron en la reforma de 1936 para la creación de nuevos departamentos fueron los siguientes:

El territorio nacional se divide en departamentos, intendencias y comisarias; y unos y otras en municipios o distritos municipales. La ley podrá decretar la formación de nuevos departamentos, siempre que llenen estas condiciones:

3 Que la solicitud de la creación de la nueva entidad haya sido solicitada por las tres cuartas partes de los concejales de la comarca que ha de formar el nuevo departamento.

4 Que el nuevo departamento tenga por lo menos 250.000 habitantes y \$ 500.000 de renta anual.

5 Que aquel o aquellos de que se segregue queden cada uno con una población de 250.000 habitantes y con una renta anual de $\$ 500.000$.

Este precepto constitucional modificó los anteriores en cuanto concierna a:

1 Que la creación del nuevo departamento sea solicitada por las tres cuartas partes de los concejales de la comarca que ha de formarlos.

2 Que el nuevo departamento tenga una renta anual de $\$ 500.000$ y que aquellos de que fuere segregado quede también con una renta anual de $\$ 500.000$ cada uno.

Además, se prescindió de la formalidad de que la creación fuese decretada por una ley aprobada en dos legislaturas anuales sucesivas ${ }^{25}$.

Al observar el contexto social y político de la época, gran parte del territorio nacional estaba sumido en la violencia bipartidista. El antiguo departamento de Bolívar fue uno de los más afectados con este tipo de violencia. Por ejemplo, en la prensa se registraron un sin número de noticias que tuvieron que ver con ello.

(...) El doctor Pineda nos relató, con viviente crudeza el clima de barbarie en que se debate el liberalismo de provincia. En su calidad de hombre y de prestante cifra de nuestro partido, el doctor Pineda nos expreso su encendida protesta en la siguiente forma:

(...) El país no tiene idea del martirio a que están sometidos los liberales por el delito de serlo. Por lo demás, no quiero, antes de regresar a Bogotá, dar a la publicidad detalladas informaciones al respecto; solo se decir que el martirio y la sangre liberal, inútilmente derramada van a ser el mejor estimulo para la aplastante victoria del partido en las próximas elecciones $(\ldots)^{26}$

A pesar de la inclemente violencia el énfasis de la división territorial no fue

\footnotetext{
${ }^{24}$ Remberto Burgos Puche, Creación y organización de Córdoba, Montería, Obregón, 1956, pp. 89.

${ }^{25}$ R. Puche, Creación y organización de Córdoba, pp. 10.

26 "La sangre liberal, inútilmente derramada, va a ser el mejor estimulo para la victoria: Dice el Dr. Néstor Pineda. Régimen de la que se avergonzarían gentes de la Edad Media", en Editora del Mar S.A. [en adelante se citará por las iniciales EM], Colección de prensa, El Universal, Cartagena, marzo 25 de 1949.
} 
echado en el olvido. Según los sectores políticos nacionales y locales era necesario "dividir para gobernar" 27. La creación o la división de los departamentos, viene a ser visto como astucia o interés político de los partidos políticos, debido a la violencia bipartidista característica del periodo. Entre tanto, la desestabilización social y la pugna política influyeron en la crisis económica en gran parte del territorio nacional.

Lo más grave que tiene esta alteración del orden público, con todo y que el gobierno de Unión Nacional [así se le llamó a la administración de Mariano Ospina Pérez 1946 - 1950] está procurando que haya el mínimo de sacrificio de las garantías constitucionales, son las repercusiones que se hacen sentir en el orden económico, originalmente afectados con mucha anterioridad a los sucesos de abril. Un estado social casi irresistible por el altísimo costo de la vida, no puede ser el más propicio para asegurar el rápido restablecimiento de la normalidad. Por el contrario, estamos asistiendo una de las crisis más profundas de nuestra estabilidad económica. Lo está indicando así el malestar general que se observa a causa del desequilibrio entre una moneda q'[ue] cada vez se desvaloriza más y el ritmo acelerado del fenómeno inflacionista con todas sus consecuencias. Los precios de los artículo[s] de principal y obligado consumo popular suben en una proporción que no tiene la menor explicación justa, ni se trata con ello de favorecer la agricultura porque existe en el fondo de todo esto una especulación en grandes escala que no ha sido posible detenerla ni reprimirla con las medidas intervencionistas del control de precios $(\ldots)^{28}$

El periodo de crisis económica que estaba viviendo la nación colombiana a finales de la década de 1940, provocó un alto déficit económico y el ciclo inflacionista estaba lastimando a toda la infraestructura económica colombiana. Para lo cual, el gobierno central instituyó una serie de nuevos impuestos en pro de solucionar esta grave crisis.

Los decretos leyes que acaban de expedirse crean algunos impuestos nuevos, como el que grava el ausentismo, la soltería y los dividendos; aumenta las tasas altas sobre la renta y complementarios, que no otra cosa es el que se denomina en el número 1961 "impuesto a grandes rentas", y restablecer el tipo de cambio diferencial para los diversos cupos de exportación, el cual rigió en otra época, aunque entonces no tuviera propiamente el carácter fiscal.

Si esos nuevos gravámenes no se acompañan de severas economías de gastos público a fin de eliminar los déficits presupuestales ya crónicos, de va a dar nuevos estímulos al ciclo inflacionista que estamos viviendo $(\ldots)^{29}$

En el período de constitución de los departamentos, existió la constante de la

\footnotetext{
${ }^{27}$ Francisco Avella. "El papel de la geohistoria para la construcción de la región Caribe", en, El Caribe en la nación colombiana. Memorias: X cátedra anual de historia Ernesto Restrepo Tirado, Bogotá, Museo Nacional de Colombia Observatorio Del Caribe, 2005, p. 106.

28 "El orden económico", en EM, El Universal, Cartagena, junio 04 de 1948.

29 "Las nuevas medidas fiscales y económicas", en EM, El Universal, Cartagena, junio 17 de 1948.
} 
prosperidad y desarrollo del centro político y de la elite que enarbolaba las aspiraciones autonomistas en el caso de Montería, debido a la actividad de la cría y comercio de ganado. Miremos la siguiente acotación periodística de un personaje anónimo de la época que habla de ello:

\begin{abstract}
Ahora es que conozco a Montería de ella había llegado hasta mí la fama de su progreso, pero en verdad, nunca di entero crédito a tales versiones, porque siempre imagine que tal progreso se refería únicamente al desarrollo de la industria pecuaria, en manos de un reducido de capitalista que los explotaban (...) pero a poco de llegar aquí cambie sustancialmente ese concepto mío y hoy me hallo convencido de que, entre las poblaciones sinuanas, Montería es la que muestra mejores posibilidades de progreso, tanto desde el punto de vista económico como el cultural $(\ldots)^{30}$
\end{abstract}

Existieron muchas acotaciones periodísticas de personajes importantes de la época hablando acerca de la prosperidad de Montería de sus medios económicos, sus necesidades básicas, infraestructura vial y el abandono por parte del gobierno etc.

El doctor Eliseo Arango, ex - leopardo, profesor de economía política y personalidad conservadora de relieve que hace pocos días estuvo de jira por Bolívar, en compañía del ex - gobernador Villareal de Boyacá y de don Manuel Ospina Vásquez se detuvo en la región del Sinú, en donde conferenció con sus copartidarios (...) el doctor Arango, gran observador y hombre de viajes, ha concedido para "El Liberal" algunas declaraciones a su regreso de su jira por estas comarcas.

Impresionado por las maravillas que encierra el Sinú, dijo al diario bogotano lo siguiente:

La región del Sinú dice es una de las más rica que he visto. Tiene actualmente una gran cantidad de ganados, y debe compensarse su desarrollo ganadero con el agrícola. Una hectárea de esta tierra sembrada de algodón o de ajonjolí da maravillosos resultados. Yo puedo decir que, si se cultiva esa riquísima tierra, Colombia puede arreglar el problema de su alimentación en un 75 por ciento. Es riquísima, pero le falta protección del estado (...) porque como no está en producción esa tierra, los servicios de higiene y demás son pocos. A este propósito dice:

Pero suceden cosas inexplicables. Montería, por ejemplo, que es una ciudad próspera y tiene una gran población, no tiene agua potable. El rico podrá tener un filtro; pero el pobre, el hombre de pueblo tiene que beber agua del río, el cual pasa a la altura de una de las avenidas de la población. Es necesario que el estado se interese por estas tierras ${ }^{31}$.

En las opiniones o entrevistas a ciertos personajes siempre se aprecia una especie de reclamo por el abandono de parte del gobierno, por una mejor inversión o de aprovechamiento de esta rica región del Sinú que le traería

30 “El porvenir de Montería”, Revista Polígrafa de Colombia. vol. 6, nº 6, 1929, pp. 11.

31 "El porvenir del Sinú", en EM, El Universal, Cartagena, julio 14 de1948. 
grandes beneficios económicos y sociales a la Nación. Con este progreso económico por el cual estaba pasando la subregión sinuana y del San Jorge inicia el interés de los antioqueños por las actividades agropecuarias e igualmente el apoyo político para la creación de una entidad departamental. Por ejemplo, de Miguel Gómez Fernández, un influyente político de la época, opinó que:

La situación de Montería:

Al preguntarle sobre las impresiones acerca de la situación económica de Montería nos contesto:

Son óptimos. Montería es un centro económico en pleno desarrollo. Su granja agropecuaria es un núcleo destinado a la multiplicación del romo sinuano autóctono, considerado como el mejor de las ganaderías suramericanas, en su calidad de raza criolla. El doctor Vicente Escobar, director del establecimiento, tuvo la gentileza de explicar la organización de la granja, la cual me pareció satisfactoria. La vacada s hermosísima. En tiempo que el ganado romo sinuano predomina ya por el número, entre sus congéneres criollos, lo cual es prometedor, para el incremento de la industria. En numerosas haciendas particulares se cruza intensamente nuestro ganado con el de las mejores razas extranjera, especialmente con el cebú y holsttein.

Un cambio de frente:

Pero se dice que en Montería y el resto del Sinú hay una tendencia a cambiar la tradición pecuaria por la agricultura, y especialmente por el cultivo de algodón (...) los monterianos se quejan de que ninguna capitalista cartagenero se haya acercado en estos momentos febriles a participar en esa revolución agrícola de que hablo, al tiempo que los hermanos Carlos y Julián Uribe Gaviria de Bogotá y Medellín, los doctores Gonzalo y Jaime Vélez Trujillo distinguidos hombres de trabajo han acudido presurosos a intervenir en el negocio del algodón $(\ldots)^{32}$

Los monterianos indicaban que el atraso en que se encontraba el resto de la subregión se debió a la mala infraestructura vial que no les permitía una buena comercialización de sus productos agropecuarios, por eso el énfasis de la construcción de vías para la región del Sinú. Esta pugna por las vías entró en candente debate con el apoyo de los antioqueños, los cuales requerían urgentemente una conexión por ferrocarril o por la carretera Troncal de Occidente, pero todo esto fue una maniobra de la aristocracia de Antioquia para tomar mayor influencia económica y política en la subregión.

(...) En Antioquia que tantos vínculos naturales tiene con nuestro departamento, se observa que, al amparo de su robusta personalidad regionalista, unas veces quiere la unión con Bolívar por el ferrocarril y otros por la carretera Troncal. Sus intereses agrícolas y ganaderos lo

32 “Una verdadera revolución agraria se está desarrollando en el Sinú: Pero no participa el capital cartagenero, impresiones del Dr. Miguel Gómez F[ernán]dez”, en EM, El Universal, Cartagena, abril 15 de1950. 
aproximan a las tierras bolivarenses, su espíritu expansionista ya llega a la parte alta del Sinú y se extiende por del San Jorge; el afán colonizador de su pueblo se siente y da pruebas magnificas de su esfuerzo, sin embargo, no se traduce en la práctica, en ninguna coordinación efectiva, sobre el plano de realización inmediata.

El empuje dinámico de Antioquia mira hacia al mar, pero tiene como objetivo Urabá, punto terminal de su carretera, y secundariamente piensa en el puerto de Cartagena a, lo sumo, en Cispata. A decir verdad, el regionalismo antioqueño es, por su vigor, digno de alabanza; pero como toda fuerza busca expansión en ámbitos propios para su natural desenvolvimiento $(\ldots)^{33}$

Como explica esta nota periodística el interés de los antioqueños por las tierras del Sinú, en lo concerniente a la compra de las propiedades de la Compañía Francesa del Sinú por parte de los hacendados empresarios y cuya adquisición tomo el nombre de Sociedad Agrícola del Sinú, cuyos mayores accionistas fueron los Ospina Vásquez y, estos a su vez eran una de las grandes familias políticas de la Nación. La afluencia de capital paisa era muy prominente en la región del Sinú y del San Jorge, e influyeron de manera directa en el despegue económico de esta región.

(...) La afluencia del capital antioqueño a Montería, de hombres de trabajo y hasta de personal docente y técnico en todos los órdenes de la vida monteriana, se está robando la admiración y el aprecio de los monterianos. Y a este respecto nosotros nos preguntamos: [i] Por qué los cartageneros no hacen lo mismo? Que de hacerlo los vínculos entre Montería y Cartagena serian más fuertes ${ }^{34}$.

Como se ha analizado, entre los argumentos básicos de la dirigencia monteriana estuvo el abandono en la que se encontraba la región sinuana por la falta de vías para la comercialización de productos agropecuarios y en sus reclamos a Cartagena, obtuvo el apoyo de los sectores sociales y políticos principalmente conservadores de Antioquia. La administración departamental sugería que el departamento no estaba en capacidades de realizar inversiones de alto costo en las provincias que lo conformaban, debido a la precaria situación económica y fiscal por la que estaba atravesando Bolívar y la Nación ${ }^{35}$, lo que exaspero, aún más, los ánimos separatistas y los reclamos eran cada vez más fuerte contra Cartagena.

(...) Existe en Montería cierto descontento con el gobierno departamental. Este descontento se ha manifestado en las actividades que en estos días está desplegando el pueblo monteriano sin distingo de colores políticos, con la cuestión del departamento del Sinú. A Montería se le está adeudando alrededor de cuatrocientos mil pesos por conceptos de auxilios y participaciones. Sumas esta que necesita urgentemente

\footnotetext{
33 "Regionalismo o nacionalismo", en EM, El Universal, Cartagena, abril 22 de1950.

34 "Gran descontento hay en el Sinú con el gobierno departamental. 400 mil pesos de le adeudan por conceptos de auxilio y de participaciones”, en EM, El Universal, Cartagena, agosto 20 de 1948.

35 "El caos fiscal en Bolívar", en EM, El Universal, Cartagena, septiembre 07 de 1948.
} 
para su alcantarillado, arreglo de calles y caminos y para resolver el problema del acueducto y la planta eléctrica. Esta despreocupación del gobierno departamental para con Montería, ciudad que vive de su trabajo, ambicioso de un constante progreso, y que siempre corresponde a Cartagena con creces en todos los órdenes de la vida administrativa $(\ldots)^{36}$

Después de observar la pugna política y de violencia; el panorama económico que atravesaba el país; los nuevos impuestos que se implementaron, el progreso de Montería y los reclamos al gobierno departamental por el abandono a que estaban sometidos, pasemos ahora a analizar cómo fue la creación del departamento de Córdoba que además de tener en cuenta las legislaciones territoriales ${ }^{37}$, el proyecto presentado ante el Senado de la República para la creación del mismo, se debe destacar la consolidación de Montería como centro político de la zona. Como se enfatizó anteriormente, en la creación de la provincia de Montería con la Ordenanza 35 del 20 de abril 1911, sancionada por la Asamblea Departamental. Debido a esto le permitió consolidar poder político y económico en la zona que le fue adjudicada. Por lo tanto, se consolidó una elite política y económica principalmente de ganaderos, que buscaron la erección del nuevo departamento, llamados La Junta Central Pro - departamento de Córdoba. Entre los integrantes se encontraban: Abel Guzmán Botero, Eugenio Giraldo, Miguel Escobar Méndez, Abraham Pupo Villa, Severo Justo García, Jacinto Fernández, Efraín Padrón, Manuel Antonio Buelvas, Jesús Rodríguez Corrales, Francisco Jattin, Rafael Chejne, Luis Alfonso Lyons, Alfonso Cabrales Pineda, Libardo López Gómez y Horacio Guzmán ${ }^{38}$.

Sin embargo, esta lucha por la autonomía hay que analizarla desde el discurso de político, ya que la junta pro - departamentalista, instalada en Montería, ideó una cantidad de alegatos que justificaban la división territorial para la creación de una entidad departamental en la región sinuana y del San Jorge. Cartagena no sólo, política y administrativamente, estaba alejada de su hinterland, lo que hacía difícil la administración de un territorio tan grande, lo que se veía en las faltas de vías de comunicación adecuadas. Todo esto se concatenaba en el discurso político de la Junta, lo que, en síntesis, exponía que para poder salir del estancamiento en que se encontraban la otrora provincia del Sinú y la provincia del San Jorge era necesario la subdivisión departamental y como lo argumentaban los promotores: "Nuestro criterio nos indicaba que la buena administración es la base del progreso y que Bolívar nada cambiaría mientras ese inmenso y desarticulado departamento existiese

\footnotetext{
36 "Gran descontento hay en el Sinú con el gobierno departamental. 400 mil pesos de le adeudan por conceptos de auxilio y de participaciones", en EM, El Universal, Cartagena, agosto 20 de 1948.

${ }^{37}$ El proyecto presentado ante el Senado de la República en 1948 entre las poblaciones estuvieron Caimito, San Benito Abad, San Marcos y el corregimiento de Coveñas que fue agregado a San Antero, después de la erección del departamento fueron reincorporadas a Bolívar. Por consiguiente, el número de habitantes fue 273250 según el censo de 1938 . Los defensores expusieron que el guarismo cambio por cálculos obtenidos de la Contraloría de la República y fue de 354940 habitantes. Las rentas según sus cálculos fueron de \$1'322.498, 48. Véase R. Burgos Puche, Creación y organización de Córdoba, pp. $78-81$

38 "Un mensaje de la Junta Central Pro - departamento de Córdoba, al Universal", en EM, El Universal, Cartagena, septiembre 14 de 1948 .
} 
como tal. La norma a seguir, para ser consecuentes con nosotros mismos, era entonces ésta: procurar la desintegración de Bolívar para que las partes en que quedara dividido prosperen" 39 . El proyecto se presentó al Congreso de la República en septiembre de 1948 en liderazgo del partido conservador y con el apoyo de los políticos liberales de la subregión como: Miguel F. de la Espriella de Sahagún, Enrique C. Flórez de San Benito Abad y Antonio Navarro Flórez de Montería.

Fue presentado el proyecto al Senado por el Dr., Burgos conservador, los limites y los municipios, con la firma del senador bolivarense doctor Remberto Burgos acaba de ser presentado a la consideración del Senado un proyecto de ley en virtud del cual se crea el departamento de Córdoba, formado del territorio que le seria segregado del Bolívar. El texto del proyecto citado, que remitido para su estudio a la Comisión Primera Constitucional del Senado $(\ldots)^{40}$

Este es el discurso manejado por la elite agropecuaria de Montería. No obstante, existía el contradiscurso de las clases políticas y económicas de Cartagena y Lorica. Según los dirigentes de Cartagena “(...) se han comprobado que se trata de una hábil maniobra política del conservatismo que han engañando a las masas y muchos elementos liberales del Sinú que de buena fe y por un prurito electoral algunos dirigentes han encontrado a hacer causa común con el conservatismo sobre el particular $(\ldots)^{41}$ ". Por esto inicia una pugna partidista en la región sinuana y del San Jorge, ambos partidos se valieron de estrategias para ganar simpatizantes y votantes para las próximas elecciones $^{42}$.

En la conformación y creación del departamento de Córdoba, se necesitaron aproximadamente tres años que van desde el año de 1948 en que se presentó el proyecto al Senado hasta finales de 1951 en que fue sancionada la Ley. En todo este periodo la disputa bipartidista se hacía sentir en todos los aspectos. Por ello en la erección de los departamentos siempre se percibía que era una astucia política o que éstos se convertirían en bastiones partidistas. Por lo tanto, en la prensa de la época se ratifica esta disputa entre los partidos, como lo declara el titular registrado en El Universal en octubre de 1948 "con el departamento de Córdoba se busca la conservatización del Sinú, declara el diputado Víctor Flórez Samudio"43. Por consiguiente, la disputa de las elites de los centros políticos se hacía sentir cada vez más en la prensa de la época ${ }^{44}$. Dependiendo de que quienes fueran los propietarios de la prensa es que se puede analizar el discurso y el contradiscurso, verbigracia, El Universal, diario cartagenero cuyo propietario era de del partido liberal colombiano y

\footnotetext{
${ }^{39}$ R. Burgos Puche, Creación y organización de Córdoba. pp. 58 -59.

40 "Proyecto de la creación del departamento de Córdoba", en EM, El Universal, Cartagena, septiembre 12 de 1948.

41 "Creación del departamento de Córdoba perjudica al Liberalismo. Así lo afirman destacados jefes del partido maniobra conservadora por lograr mayoría”, en EM, El Universal, Cartagena, octubre 02 de 1948.

42 "Todo el liberalismo del Sinú en la gran concentración de hoy", en EM, El Universal, Cartagena, abril 02 de 1949.

43 "Con el departamento de Córdoba se busca la conservatización del Sinú", en EM, El Universal, Cartagena, octubre 31 de 1948.

44 "El liberalismo de las Sabanas en pie al paso de la Dirección N[acion]al del partido", en EM, El Universal, Cartagena, abril 26 de 1949.
} 
miembro del Senado de la República por parte del departamento de Bolívar y uno de los representantes más pudientes de Cartagena Domingo López Escauriaza. Por lo tanto, se hace sentir el acérrimo contradiscurso en contra de la erección del nuevo departamento, que fue catalogado como un proyecto inaceptable ${ }^{45} \mathrm{y}$, de igual forma, algo que atentaba la unidad departamental como los regentes cartageneros lo denominaban la "Desintegración Territorial de Bolívar" 46 . Como el centro político y rival era la ciudad de Cartagena que defendía su mítica soberanía sobre el hinterland que buscaba separarse de ella. Miremos este contradiscurso perpetrado por otro de los grandes representantes de la elite cartagenera, el senador bolivarense Efraín S. del Valle, presidente de la Comisión Tercera del Senado.

En unión con el senador Pretelt Martínez, les informo [el senador Efraín S. del Valle Presidente de la Comisión Tercera del Senado] para que a su vez se sirvan publicar que el senador Burgos presento ayer, y fue repartido hoy a la Comisión Primera, el proyecto que tiende a crear el departamento de Córdoba, desmembrando el territorio de Bolívar. No era tan infundada como lo observara algún corresponsal la primera información que permite darles sobre este interesante tema.

Como voceros del departamento de Bolívar tanto el senador Pretelt como el suscrito, deseamos que la prensa escrita y hablada inicie campaña defendiendo la integridad territorial de nuestro histórico departamento y que exciten al pueblo de Bolívar en el sentido que nos suministre toda clase de datos para contrarrestar la acción desmembradora. Especialmente excitamos a la Contraloría General del Departamento para que nos envíe a la mayor brevedad, datos referentes a la población, acompañado del valioso concepto sobre la conveniencia e inconveniencia de la iniciativa desmembradora. Suponemos que el senador Romero Aguirre compartirá nuestro punto de vista, porque estamos dispuestos los senadores Pretelt Martínez y el suscrito a liberar la batalla porque se mantenga la integridad de Bolívar ${ }^{47}$.

Tomando el contenido de los fundamentos de las clases notables de Cartagena en representación de sus más pudientes miembros, encontramos siempre la misma perspectiva, que era la defensa integral del territorio del histórico departamento de Bolívar. Cuando se inicia el movimiento que buscaba crear el departamento de Córdoba, la elite de Cartagena lo llamaba el conato separatista.

En relación con el movimiento que ha estado agitándose en Montería a favor de la creación de un nuevo departamento a expensas de Bolívar, hemos recibido las siguientes comunicaciones:

Bogotá septiembre $1^{\circ}$ de 1948.

El Universal Cartagena.

Creo de mí deber denunciarles que se agita en la Cámara de Representantes un conato de desmembración de nuestro departamento

\footnotetext{
45 “Un proyecto inaceptable", en EM, El Universal, Cartagena, septiembre 12 de 1948.

46 "Desintegración Territorial de Bolívar", en EM, El Universal, Cartagena, septiembre 14 de 1948.

47 “Defensa de la integridad de Bolívar", en EM, El Universal, Cartagena, septiembre, 08 de 1948.
} 
dizque para fundar, con la región sinuana y parte de sabanas un nuevo departamento llamado 'Córdoba'.

Por respetable que sean los móviles de los iniciadores de la desmembración, me parece que las voces de la opinión pública debieran abrir un plebiscito, máxime cuando acabo de recibir una airada voz de protesta de los habitantes de Lorica, cuyo gallardo gesto de solidaridad para con Cartagena, me ha conmovido la voz de los pueblos ${ }^{48}$.

Este movimiento que buscaba la erección de un nuevo departamento en la subregión sinuana y en el San Jorge, fue visto como proselitismo político y una astucia del partido conservador en conseguir curules en el Senado. Igualmente se percibía como una disputa entre los distintos sectores políticos ${ }^{49}$. Por consiguiente, el respaldo incondicional de los sectores políticos especialmente la bancada conservadora en el Senado del departamento de Antioquia se hizo sentir en la proyectada erección de la nueva entidad administrativa en el período de 1948-1951. Este apoyo incondicional de gran parte de la elite antioqueña, se debió a las relaciones políticas, económicas y comerciales (especialmente la actividad comercial de ganado vacuno) que se crearon con la migración de muchas familias pudientes a las regiones del Sinú y del San Jorge. En donde estas adquirieron muchas tierras aptas para la ganadería y otras actividades agropecuarias y, por consiguiente, los antioqueños residentes en el Sinú, estuvieron directamente relacionados con la intención de una nueva división territorial, que buscó la creación de un nuevo departamento para así, favorecer sus intereses económicos, comerciales y políticos ${ }^{50}$.

En la creación del departamento de Córdoba percibimos el interés de los sectores políticos y económicos a la hora de forma unas coaliciones a favor o en contra de este propósito como lo presentaba el titular de la prensa en septiembre de 1948:

(...) que el proyecto separatista o de creación del nuevo departamento del Sinú será negado en la Comisión Primera de la Cámara de Representantes. No será ni siquiera aceptado, formalidad indispensable y que requiere las dos terceras partes de los votos de los miembros de dicha comisión.

Interrogando a un personaje del Sinú nos declaró que dicho proyecto es apenas una maniobra política que se tomará como bandera en la próxima campaña electoral por el grupo conservador del burguismo [grupo liderado por los Burgos] y con la finalidad de tomar posiciones con el fin de derrotar el veguismo. Naturalmente prosigue nuestro entrevistado, algunos personajes liberales con el fin de poseer curules o de obtener la reelección están haciendo eco a esa campa[ñ]a separatista con finalidades electorales.

\footnotetext{
48 "Movimiento en el Sinú para la creación del departamento de Córdoba. Los habitantes de Lorica envían su protesta n[acion]al por el conato separatista", en EM, El Universal, Cartagena, septiembre 03 de 1948.

49 “10000 liberales en la gran concentración de Montería”, en EM, El Universal, Cartagena, abril, 03 de1949.

${ }^{50}$ Orlando Fals Borda, Historia doble de la costa: Retorno a la tierra, Bogotá, Universidad Nacional, 2002, pp. 117a $118 \mathrm{a}$.
} 
Como dirigente del movimiento separatista se halla en Bogotá el se[nad]or Benjamín Burgos, jefe conservador de Berástegui, y quien viene desarrollando una campaña a favor de dicho proyecto $(\ldots)^{51}$

En el proyecto y creación del departamento del Sinú o Córdoba, como fue llamado más adelante, fue muy importante el liderazgo de la familia Burgos y su coalición mayormente del partido conservador, el respaldo político de algunos jefes liberales de la subregión ya mencionados y de altos jerarcas políticos de la Nación de ambos partidos como: el mismo presidente de Unión Nacional, el conservador Mariano Ospina Pérez, los miembros del Directorio Nacional Conservador Luis Navarro Ospina, Gilberto Alzate Avendaño y Augusto Ramírez Moreno y los conservadores José M. Bernal, ministro de Hacienda y Crédito Público, el ministro de Trabajo Evaristo Sourdis, los liberales, el ministro de Economía Nacional, Pedro Castro Monsalvo y el ministro de Gobierno Darío Echandía.

La clase dirigente de Cartagena percibía esto como una forma de hacer campaña para las próximas elecciones. De allí que éstos argumentaron que los Burgos tomaron como bandera de su campaña política la creación del nuevo departamento. Todos estos discursos son expuestos en la prensa de la época y con mayor asiduo en los debates de las sesiones del Congreso de la República entre los años de 1948 y 1952.

Como el objetivo era separarse jurisdiccionalmente de Cartagena, en páginas anteriores explicamos cómo se convirtió Montería en cabecera de esta subregión. Esto originó una disputa entre Lorica y Montería por la soberanía y la influencia en esta zona de la Región Caribe. Al constituirse la Provincia de Montería, Lorica que era la cabecera importante del Sinú cayó como centro importante tanto en lo político como en lo económico. Aunque el discurso de la elite de Lorica es en cierta forma parecido al de Cartagena, obedece más a la defensa de su antigua prestancia política sobre la subregión del Sinú. La clase política de Lorica sabía el poder que había alcanzado Montería y, por lo tanto, buscaron un aliado estratégico y este era Cartagena. De allí el contenido de su persistente discurso en el cual defendía su integración a Bolívar y Cartagena.

(...) sabemos que varios municipios están gestando la creación del departamento del Sinú, con cabecera Montería, aspiración que no obstaculizamos; pero queremos hacer saber al Senado y a la Cámara que el municipio de Lorica desea seguir integrado al departamento de Bolívar, por considerar que su separación de Cartagena perjudicaría enormemente su progreso, ya que el resurgimiento de una nueva ciudad capital donde todo falta, exigiría la totalidad de las rentas para hacer llegar su progreso material al nivel de las otras capitales con lesión enorme de las demás poblaciones del nuevo departamento $(\ldots)^{52}$

\footnotetext{
51 "Será negado el proyecto separatista del Sinú. Sólo se trata de una maniobra de los Burgos para derrotar a los de la Vega", en EM, El Universal, Cartagena, septiembre 10 de 1948.

52 "Movimiento en el Sinú para la creación del departamento de Córdoba. Los habitantes de Lorica envían su protesta n[acion]al por el conato separatista", en EM, El Universal, Cartagena,03, septiembre 03 de 1948.
} 
Ahora bien, en el municipio de Lorica se establece la Junta Pro - lorica que más tarde recibiría el nombre de Junta Anticordobista que va a constituirse en rival acérrimo del Sinú, que contará con el apoyo de Cartagena y del sector notable más prestante de Bolívar que está en contra de la creación del nuevo departamento. Por lo tanto, la estrategia del discurso era la defensa de la integridad territorial de Bolívar. Igualmente estaba en contra de la creación de un nuevo departamento cuya cabecera o líder del movimiento era precisamente su rival en el Sinú; Montería. Por eso su defensa era que "solamente en Lorica la ciudad [este apelativo, es simplemente una estrategia política debido a que está en si no es una ciudad] y madre del Sinú y una de las más ricas de mejor porvenir económico en la república, se nos recibió con manifestaciones en contra de la creación (...) “53

En todo este período se va a sentir el contradiscurso y las estrategias de la clase política de Lorica que va a defender a capa y espada, la no creación de este nuevo departamento, contando con el apoyo de la mayoría de los dirigentes de la ciudad de Cartagena. Esta lucha de Lorica en contra de Montería en la creación del nuevo departamento se hacía sentir en la prensa. Por ejemplo, el titular del mes de septiembre de 1948: "manifestación de protesta en Lorica ante los separatistas; gritos de 'viva Cartagena', 'viva Lorica', no queremos la separación del departamento" 54 . La táctica de Lorica se va hacer sentir aun en los estrados de mismo Gobierno Central; que van argüir de cualquier forma que los procedimientos para la creación del nuevo departamento han hecho a un lado los preceptos constitucionales y que en cierta forma no cumple los requisitos exigidos por las leyes de división territorial. Cuando fue sancionada la Ley que creó el departamento de Córdoba en diciembre de $1951^{55}$, la repuesta de Lorica aludió que "la Ley que creó a Córdoba hizo a un lado como una cosa vetusta la Constitución Nacional. Dice el doctor Gabriel Carreño Mallarino en la demanda presentada ante la Corte" 56 .

En el año de 1952 se hace sentir más las voces de protesta, pero a nivel de demandar la Ley que creó el nuevo departamento al Gobierno Central, en el aspecto que en la formación y creación del nuevo departamento se violaron los requisitos legales para su erección. Por eso los titulares de prensa siempre hablan de dicha demanda, encabezada por la junta Anticordobista establecida en el municipio de Lorica en ese mismo año. Veamos la demanda que fue encabezada por uno de los antagonistas a la creación del departamento de Córdoba Jesús H. de León Martínez, miembro de la clase política de Lorica y, a su vez, de la Junta Anticordobista.

\footnotetext{
53 "Supresión de Lorica del proyecto sobre el departamento de Córdoba. Los habitantes de esa ciudad se dirigen al Presidente del Senado para solicitárselo", en EM, El Universal, Cartagena, octubre 28 de 1948.

54 "Manifestación de protesta en Lorica ante los separatistas", en EM, El Universal, Cartagena, septiembre 30 de 1948.

55 "Ley número 9 de 1951. Por el cual se organiza el departamento de Córdoba", AHC, Diario Oficial, Bogotá, diciembre 18 de 1951.

56 "La Ley que creó a Córdoba hizo a un lado como una cosa vetusta la Constitución Nacional", en EM, El Universal, Cartagena, marzo 15 de 1952.
} 
El pupitrazo que significó la creación del nuevo departamento de Córdoba contra el querer de casi la totalidad de las poblaciones que lo integran no puede ser epilogo feliz para los separatistas, y así como a pesar del aspecto legal que se le dio a la desmembración de Bolívar, han surgidos brotes de inconformidad que ponen de presente la base falsa en que se afirma la constitución de esa nueva entidad política administrativa (...) la mencionada junta se propone demandar ante la Corte Suprema de Justicia la Ley [Ley 9 de 1951] que creó el nuevo departamento por considerarla inconstitucional, ya que con el regreso homogéneo que la aprobó paso por alto esenciales requisitos constitucionales; como el de la solicitud por las tres cuartas partes de los concejales de la comarca [el territorio del departamento], lo cual no sucedió. Sólo se llevo a cabo una maniobra en que la que figuraron firmas de antiguos ediles, de suplentes y de individuos que no representaban a los municipios.

Por otra parte, no sólo Lorica se halla agitada en torno a este movimiento. En otras poblaciones de esa región, especialmente en el bajo Sinú, existe un visible entusiasmo por llevar adelante la acción que habrá de echar abajo los propósitos divisionistas $(\ldots)^{57}$

Estas voces de protestas hechas por los líderes de la Junta Anticordobista, buscaron obstaculizar la erección del nuevo departamento, pero, como se había resaltado anteriormente, esto era una maniobra política de la clase dirigente de Lorica con en el patrocinio de la de Cartagena. Por lo tanto, arguyeron de que en la creación de este departamento. La Ley, 'una compilación de mentiras y de violaciones de la Constitución y las leyes', el doctor Carreño Mallarino, apoderado del comité Anticordobista, presentó hoy ante la Corte Suprema de Justicia, la demanda que basada en una documentación incontestable elaboró para pedir la nulidad de la Ley que creó el departamento de Córdoba" 58 .

Los problemas entre Montería y Cartagena, después de la instauración del departamento de Córdoba, ya no tenían el mismo propósito de pedir la nulidad de la Ley 9a de 1951, pero si jurisdiccionales, como el de Coveñas "al departamento de Bolívar pertenece Coveñas no a Córdoba (...) Coveñas pertenece al municipio de Tolú. Departamento de Bolívar, quedándose definida la situación del corregimiento de Coveñas (...)"59

En las conclusiones de este período de 1948-1952, que significó la institucionalización del departamento de Córdoba, se pueden analizar dos cosas substanciales: la táctica política empleada por la dirigencia sinuana, monteriana y la coalición bipartidista. En la estrategia se percibieron los reclamos que se hacían a la administración departamental por causa del abandono en que estaba sumida la subregión sinuana y del San Jorge, y que

\footnotetext{
57 "Por inconstitucional, demandaran la Ley sobre el departamento de Córdoba. Ante la Corte Suprema de Justicia”, en EM, El Universal, Cartagena, febrero 27 de 1952.

58 "Ayer fue presentada la demanda contra el departamento de Córdoba", en EM, El Universal, Cartagena, marzo 12 de 1952.

59 “Al departamento de Bolivar pertenece Coveñas, no a Córdoba”, en EM, El Universal, Cartagena, julio 08 de 1952.
} 
se constituyeron en las bases elementales que justificaron la búsqueda de una nueva división territorial en el departamento de Bolívar.

En la coalición bipartidista se puede apreciar el interés político y económico, de los miembros de los partidos a la hora de estar a favor o no de la creación de una entidad departamental. La elite bipartidista gestora de la creación y organización del departamento de Córdoba se valió, además, de los elementos que justificaban la fragmentación del antiguo departamento de Bolívar, de la negociación con las altas esferas gubernamentales de los partidos liberal y conservador, buscando el apoyo político suficiente en el Congreso de la República para que se aprobara el proyecto de ley. El otro interés es suscitado por la alianza de Lorica y Cartagena que señaló que con la nueva división territorial se buscó la desintegración territorial de su histórico departamento y que perjudicaba considerablemente su progreso. Por lo tanto, ambas coaliciones tenían bien definidos sus propósitos en la región del Sinú y del San Jorge, que van desde estatus social, hasta el prestigio político y económico.

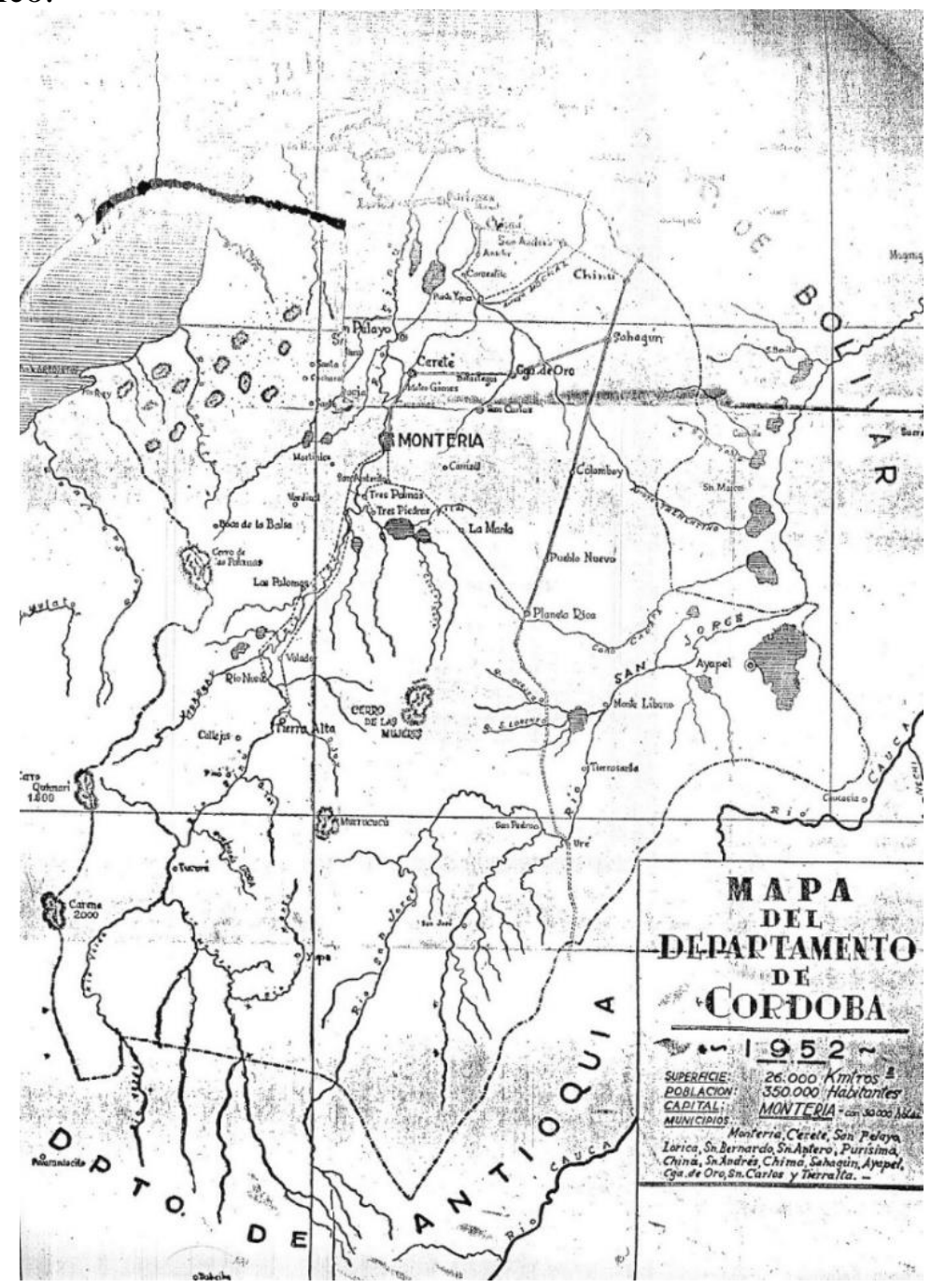

Fuente: Electo Cáliz Amador, Geografía del departamento de Córdoba. Montería, s.n., s.f, pp. 4. 
Figura 1. Los promotores del departamento de Córdoba.

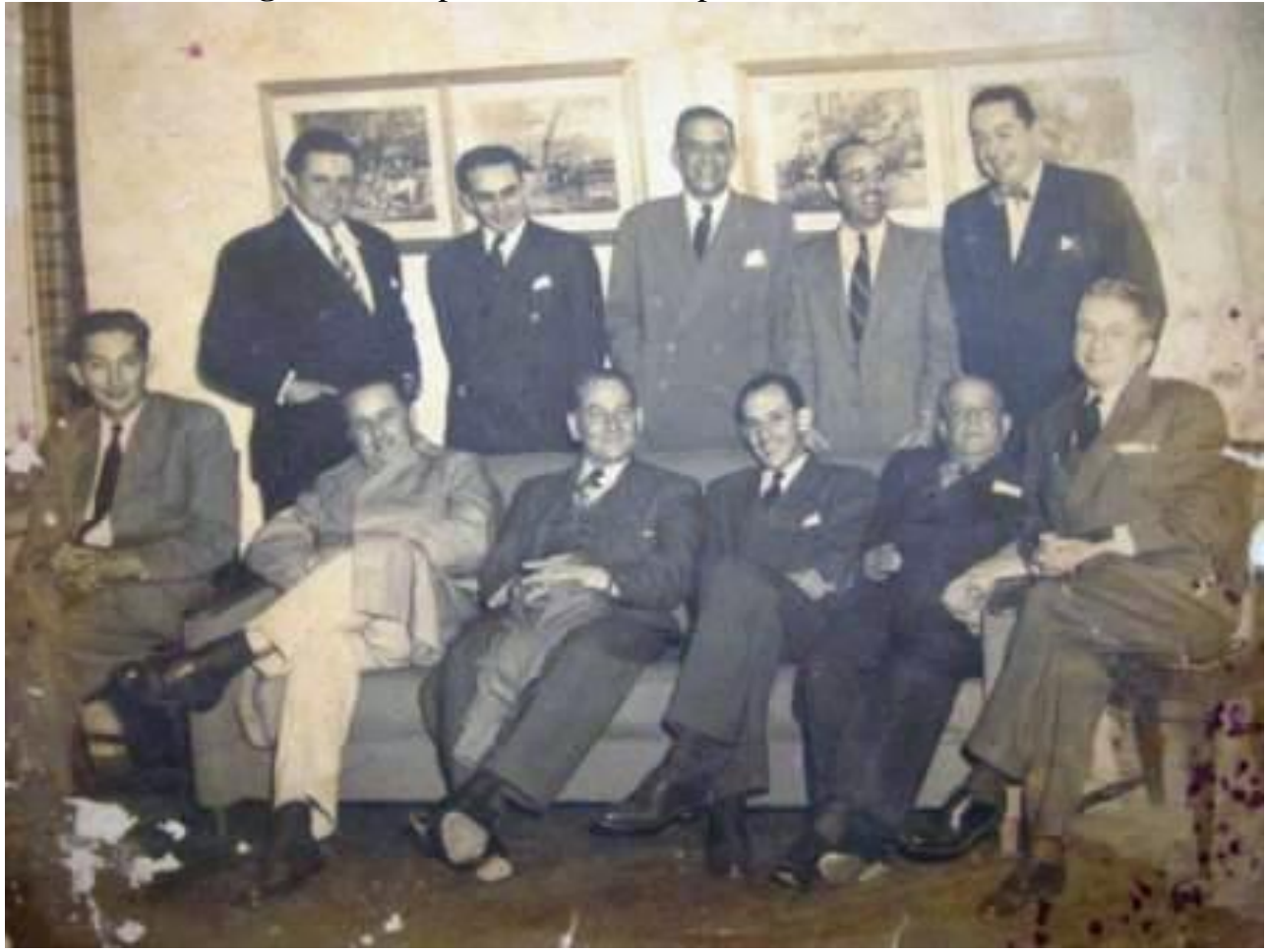

Fuente: Los promotores del departamento de Córdoba, [en línea]. Montería, Gobernación de Córdoba, [Consultado 20 de diciembre de 2010]. Disponible en internet: http://www.sahaguncordoba.com/web/index.php?option=com content\&view=article\&id=5 $5 \&$ Itemid $=73$ En su orden de pie: Alfonso Cabrales Pineda, Rosendo Garcés Cabrales, Luis Carlos Berrocal Lobo, Eugenio Giraldo Revueltas y Eusebio Cabrales Pineda. Sentados: Manuel Antonio Buelvas Cabrales, Abel Guzmán, Abraham Pupo Villa, Miguel Escobar Méndez, Alcides Bru y Remberto Burgos Puche.

\section{Bibliografía}

\section{Fuentes Primarias}

Archivo histórico de Cartagena (AHC): Diario Oficial, Bogotá, 1908, 1909; Gaceta Departamental, Cartagena, 1908, 1909, 1910, 1911, 1923.

Editora Del Mar S.A. (EM): El Universal, Cartagena, 1948, 1949, 1950, 1951.

Biblioteca Luis Ángel Arango, Sede Montería

Revista Polígrafa de Colombia. vol. 6, nº 6, 1929, pp. 11.

\section{Fuentes Secundarias}

Álvarez Llanos, Jaime. El liberalismo en el departamento del Atlántico 1905 - 1922, Barranquilla, Universidad del Atlántico, 2002, pp.179.

Avella, Francisco, El papel de la geohistoria para la construcción de la región Caribe, En, El Caribe colombiano en la nación colombiana. Memorias: X cátedra 
anual de historia Ernesto Restrepo Tirado, Bogotá, Museo Nacional de Colombia - Observatorio del Caribe, 2006, pp. 106 - 122.

Burgos Puche, Remberto, Creación y organización de Córdoba, Montería, Obregón, 1956, pp. 487.

Burgos Puche, Remberto, El General Burgos, Cartagena, Instituto Internacional de Estudios del Caribe, 2000, pp. 417.

Conde Calderón, Jorge, Espacios sociedad y conflictos en la Provincia de Cartagena 1740 - 1815, Barranquilla, Universidad del Atlántico, 1999, pp. 146.

Exbrayat, Jaime, Historia de Montería, Montería, Imprenta Departamental, 1971, pp. 272.

Fals Borda, Orlando, Historia doble de la costa: Retorno a la tierra, Bogotá, Universidad Nacional, 2002, pp. 234.

Herrera Ángel, Marta, Ordenar para controlar: Ordenamiento espacial y control político en la Llanuras del Caribe y en los Andes Centrales neogranadinos, Siglo XVIII, Bogotá, Academia Colombiana de Historia - Instituto Colombiano de Antropología e Historia, 2002, pp. 343 